\title{
Metabolism of Reactive Oxygen Species Is Attenuated in Leghemoglobin-Deficient Nodules of Lotus japonicus
}

\author{
Catrin Günther, Armin Schlereth, Michael Udvardi, and Thomas Ott \\ Max-Planck-Institute of Molecular Plant Physiology, Am Mühlenberg 1, D-14471 Golm, Germany
}

Submitted 13 June 2007. Accepted 9 July 2007.

\begin{abstract}
Leghemoglobins together with high rates of respiration are believed to be major sources of reactive oxygen species (ROS) in root nodules of leguminous plants. High capacities of antioxidative systems apparently protect this organ from oxidative damage. Using leghemoglobin-RNA interference (LbRNAi) lines of Lotus japonicus, we found that loss of leghemoglobin results in significantly lower $\mathrm{H}_{2} \mathrm{O}_{2}$ levels in nodules. Transcript levels and catalytic activities of ascorbate-glutathione cycle enzymes involved in $\mathrm{H}_{2} \mathrm{O}_{2}$ detoxification as well as concentrations of reduced ascorbate were also altered in LbRNAi nodules. Thus, symbiotic leghemoglobins contribute significantly to ROS generation in functional nodules.
\end{abstract}

Symbiotic nitrogen fixation (SNF) by rhizobia in legume root nodules is an energy-intensive process that requires $\mathrm{O}_{2}$ for respiration to generate ATP and reducing equivalents for the reduction of $\mathrm{N}_{2}$ to $\mathrm{NH}_{3}$ (Marchal and Vanderleyden 2000). Paradoxically, the nitrogenase enzyme that catalyzes this reaction is inactivated by $\mathrm{O}_{2}$ not only in rhizobia but also in other nitrogenfixing prokaryotes. Resolution of this paradox is achieved in a variety of different ways in various organisms, including temporal and spatial separation of nitrogenase activity from photosynthesis in the coccoid cyanobacterium Gloeocapsa and in Anabaena cylindrica, respectively (Robson and Postgate 1980). In legume root nodules, bacteroid nitrogenase is protected from $\mathrm{O}_{2}$ by reducing intracellular $\mathrm{O}_{2}$ concentration from approximately $250 \mu \mathrm{M}$ (the equilibrium concentration of $\mathrm{O}_{2}$ in water) to a steady-state level of less than $50 \mathrm{nM}$ in rhizobia-containing plant cells (Appleby 1984; Bergersen 1996; Hunt and Layzell 1993). This is achieved, in part, by limiting the rate of $\mathrm{O}_{2}$ influx through the outer, uninfected cell layers of the nodule and by maintaining high rates of respiration in mitochondria and bacteroids in the infected cells of the central tissue (Bergersen 1996; Bergersen and Goodchil 1973; Denison and Layzell 1991; Sheehy et al. 1985; Tjepkema and Yocum 1974; Webb and Sheehy 1991; Wittenberg et al. 1972, 1974; Witty and Minchin

Corresponding author: Thomas Ott; E-mail: Thomas.Ott@toulouse.inra.fr; Telephone: +33 561285 327; Fax: +33 561285061 .

Current address for C. Günther: Hortresearch, Flavour Biotechnology Department, 120 Mt Albert Road, Sandringham, Auckland 1025, New Zealand.

Current address for M. Udvardi: Plant Biology Division, Samuel Roberts Noble Foundation, 2510 Sam Noble Parkway, Ardmore, 73401 OK, U.S.A.

Current address for T. Ott: Laboratoire des Interactions Plantes Microorganismes, UMR CNRS-INRA 2594/441 (LIPM), Chemin de BordeRouge-Auzeville, 31326 Castanet Tolosan cedex, France.
1998). Maintenance of high respiration rates in nodule tissue requires a third factor, namely the $\mathrm{O}_{2}$-binding protein leghemoglobin (Lb), which, when present at millimolar concentrations in the cytoplasm as it is in infected nodule cells (Appleby 1984; Hargrove et al. 1997; Wittenberg et al. 1972), delivers $\mathrm{O}_{2}$ efficiently to mitochondria and bacteroids for respiration while buffering free $\mathrm{O}_{2}$ in the nanomolar range (Appleby 1984; Dakora 1995). The essential role of Lb in this 'oxygen-juggling act' for SNF was demonstrated recently when it was shown that an absence of Lb in RNA-interference (RNAi) lines of Lotus japonicus was accompanied by an increase in free $\mathrm{O}_{2}$ and a loss of nitrogenase and nitrogen fixation in nodules (Ott et al. 2005). The importance of Lb in SNF in legumes is also underlined by the facts that the symbiotic clade of plant hemoglobins has expanded greatly in this family (Bogusz et al. 1988; Trevaskis et al. 1997), Lb genes are expressed in a nodule-specific manner (Barker et al. 1988; Davidowitz et al. 1994; Gallusci et al. 1991; Ott et al. 2005; Sato et al. 2001; Stougaard et al. 1987; Uchiumi et al. 2002), and Lb genes are among the most highly expressed of all plant genes in nodules (Colebatch et al. 2002, 2004; El Yahyaoui et al. 2004; Fedorova et al. 2002; Journet et al. 2002; Kouchi et al. 2004).

Despite the apparent necessity of Lb for SNF, this family of heme-containing proteins is believed to contribute to general oxidative stress in nodules (Becana and Klucas 1992a and b; Becana and Rodriguez-Barrueco 1989; Becana et al. 1998, 2000; Fridovich 1976; Moreau et al. 1996; Puppo and Halliwell 1988a; Puppo et al. 1981; Schneider and Schlegel 1981). Ferro$\mathrm{Lb}\left(\mathrm{Lb}^{2+}\right)$, which is the active, oxygen-binding form, undergoes spontaneous autooxidation to inactive ferric- $\mathrm{Lb}^{3+}$ (Becana et al. 2000). Concomitantly, heme-bound oxygen molecules are reduced and released as superoxide anions $\left(\mathrm{O}_{2}{ }^{-}\right)$. Active $\mathrm{Lb}^{2+}$ can be regenerated from $\mathrm{Lb}^{3+}$ by the action of ferric-Lb reductase in nodules (Ji et al. 1992). Plant cells are well-equipped to deal with partially reduced forms of $\mathrm{O}_{2}$, which include $\mathrm{O}_{2}{ }^{-}$, hydrogen peroxide $\left(\mathrm{H}_{2} \mathrm{O}_{2}\right)$, and the hydroxyl radical $\left(\mathrm{HO}^{*}\right)$. These molecules are also known as reactive oxygen species (ROS) because of the oxidative damage they cause to various cellular components. The enzymatic armory possessed by plant cells to deal with ROS includes superoxide dismutase, catalase, ascorbate peroxidase (APX), monodehydroascorbate reductase (MDAR), dehydroascorbate reductase (DHAR), and glutathione reductase (GR). The sequential action of APX, MDAR, DHAR, and GR constitutes the ascorbate-glutathione cycle, which is believed to be the main pathway for ROS detoxification in plant tissues (Mittler 2002; Noctor and Foyer 1998), including nodules (Dalton et al. 1986; Matamoros et al. 2003). The antioxidant ascorbate is a key substrate for the ascorbate-glutathione cycle and is present at millimolar concentrations in functional root nodules (Dalton et al. 1986; Gogorcena et al. 1995; Matamoros et al. 1999). 
Despite the belief that Lb are a major source of ROS in nodules, this has never been tested directly in planta. The existence of two independent LbRNAi lines of Lotus japonicus that completely lack Lb in nodules enabled us to test this idea for the first time. As both LbRNAi lines exhibited identical phenotypes with respect to nodule development and function as well as plant growth and development (Ott et al. 2005), we chose to focus on one representative line in the present study. Here, we present data on the concentrations of $\mathrm{H}_{2} \mathrm{O}_{2}$ and ascorbate and the levels of transcript, protein, and activity of enzymes of the ascorbate-glutathione cycle throughout development of wildtype and LbRNAi nodules, which support the notion that $\mathrm{Lb}$ are a significant source of ROS in nodules.

\section{RESULTS}

\section{$\mathrm{H}_{2} \mathrm{O}_{2}$ and ascorbate concentrations are reduced in LbRNAi nodules.}

Concentrations of $\mathrm{H}_{2} \mathrm{O}_{2}$ and reduced ascorbate were measured photometrically in developing nodules. While no difference in $\mathrm{H}_{2} \mathrm{O}_{2}$ concentration between wild-type and LbRNAi nodules was detected 2 weeks postinoculation (wpi), significantly less $\mathrm{H}_{2} \mathrm{O}_{2}$ was found in LbRNAi nodules 3 and 4 weeks after inoculation. Concentrations of $\mathrm{H}_{2} \mathrm{O}_{2}$ were approximately 40 and $60 \%$ lower in LbRNAi nodules 3 and 4 wpi, respectively (Fig. 1A). No changes in $\mathrm{H}_{2} \mathrm{O}_{2}$ concentrations were found over time in wild-type nodules.

Total concentrations of reduced ascorbate were significantly induced in LbRNAi nodules, with increases of $36 \%$ at $2 \mathrm{wpi}$ and $22 \%$ at 4 wpi (Fig. 1B). Overall ascorbate concentrations did not change over time in both genotypes.

\section{Expression of ascorbate-glutathione cycle genes is altered in LbRNAi nodules.}

As significant changes in $\mathrm{H}_{2} \mathrm{O}_{2}$ and ascorbate concentrations were found in LbRNAi nodules relative to the wild type (Fig. 1), genes encoding enzymes involved in the ascorbateglutathione cycle in Lotus japonicus were identified using the Gene Index Project for further studies. Genes were chosen based on their representation by expressed sequence tags from nodules. Thus, sequences of the two most abundant genes encoding ascorbate peroxidases in nodules represented by tentative consensus sequences TC7951/TC7952 (LjAPX1) and TC9623 (former TC779; LjAPX2) were selected for further analyses. The latter was previously found, by cDNA-array analysis, to be induced during nodule development (Colebatch et al. 2004). Genes encoding other enzymes of the ascorbate- glutathione cycle were also chosen for expression analysis, including a dehydroascorbate reductase (LjDHARl encoded by TC17380), three monodehydroascorbate reductases (LjMDARI, LjMDAR2, and LjMDAR3 corresponding to TC12910, TC19086, and TC15657, respectively), and three glutathione reductases ( $L j G R 1, L j G R 12$, and $L j G R 13$ corresponding to TC19332, TC11942, and TC16174, respectively).

Expression of nine genes, LjAPX1 and LjAPX2, LjDHARI, $L j M D A R 1$ through $L j M D A R 3$, and $L j G R 1$ through $L j G R 3$, was measured 2, 3, and 4 wpi, using quantitative reverse transcriptase-polymerase chain reaction (qRT-PCR). Transcript levels were normalized to $L j U B I 10$, a constitutively expressed ubiquitin gene used previously for this purpose (Colebatch et al. 2002). Expression of cytosolic $\operatorname{Lj} A P X 1$ was significantly lower in LbRNAi nodules than in wild-type nodules at 4 wpi but not at earlier developmental stages (Fig. 2). LjAPX2 expression was significantly lower in LbRNAi nodules than in wild-type nodules at 3 wpi but not at other stages (Fig. 2). In contrast, transcript levels for $\mathrm{Lj} M D A \mathrm{R} 1$ and $\mathrm{Lj} M D A \mathrm{R} 2$ were unaltered in LbRNAi nodules as compared with the wild type (Fig. 2), while significantly more LjMDAR3 transcripts were detected in LbRNAi nodules than in those of the wild type at 3 and 4 wpi (Fig. 2). Significant reductions in transcript levels were also found for LjDHAR 1 in LbRNAi nodules 2 and $3 \mathrm{wpi}$, as compared with the wild-type (Fig. 2), while no significant differences between LbRNAi and wild-type nodules were found with respect to transcript levels of the three $L j G R$ genes (Fig. 2).

\section{Changes in ascorbate-glutathione cycle enzyme activities in LbRNAi nodules.}

As enzymes involved in ROS detoxification were previously found to be posttranscriptionally regulated (Contour-Ansel et al. 2006; Madhusudhan et al. 2003; Mittler et al. 1998; Shigeoka et al. 2002; Sunkar et al. 2006), we extended our analysis of ROS metabolism in nodules to measurements of enzyme activity. Analysis of the same biological material used for gene-expression analysis revealed significant reductions in APX activity in nodules of LbRNAi plants as compared with those of wild type, with 30 and $40 \%$ reduction at 3 and 4 wpi, respectively. No significant difference in APX activity was found between the two genotypes at 2 wpi (Fig. 3).

MDAR activity was significantly higher in LbRNAi nodules than in the wild type, i.e., 68,43 , and $38 \%$ higher at 2,3 , and 4 wpi, respectively (Fig. 3). A similar pattern was observed for DHAR activity, which was 69,53 , and $46 \%$ higher in LbRNAi nodules than in wild-type nodules at 2,3 , and 4 wpi, respectively (Fig. 3).

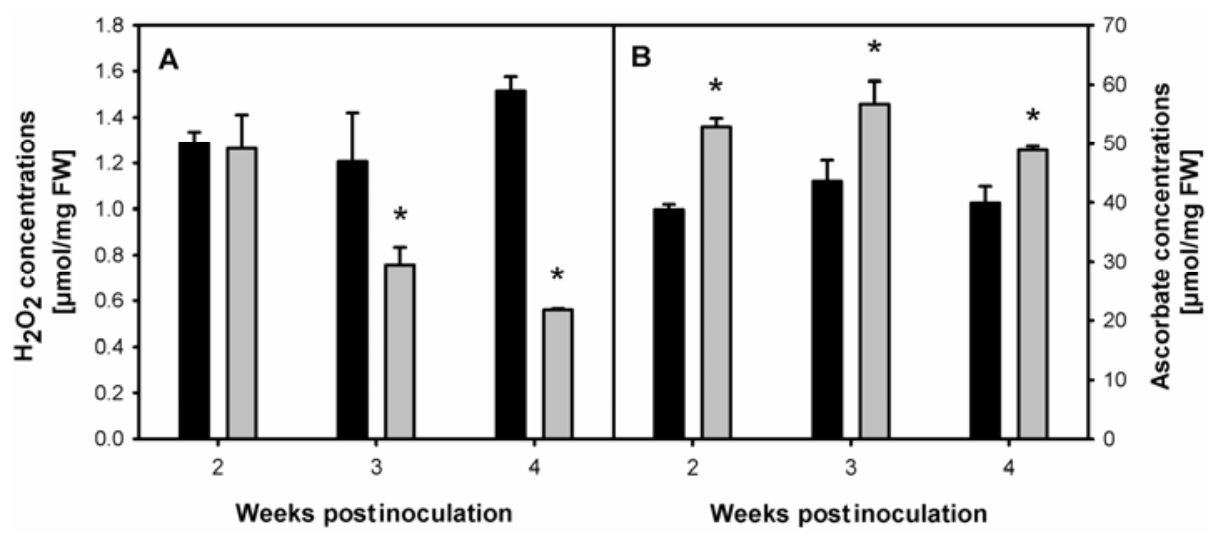

Fig. 1. Total ascorbate and hydrogen peroxide $\left(\mathrm{H}_{2} \mathrm{O}_{2}\right)$ concentrations in nodules of wild-type and leghemoglobin-RNA interference (LbRNAi) plants. Nodules were harvested at different timepoints. A, Levels of $\mathrm{H}_{2} \mathrm{O}_{2}$ and $\mathbf{B}$, total ascorbate concentrations were measured on the same set of samples. Black bars represent wild-type and gray bars LbRNAi nodules. Error bars indicate variation between three independent biological replicates. Significant differences obtained by student $t$-test $(P<0.05)$ are marked by an asterisk. 


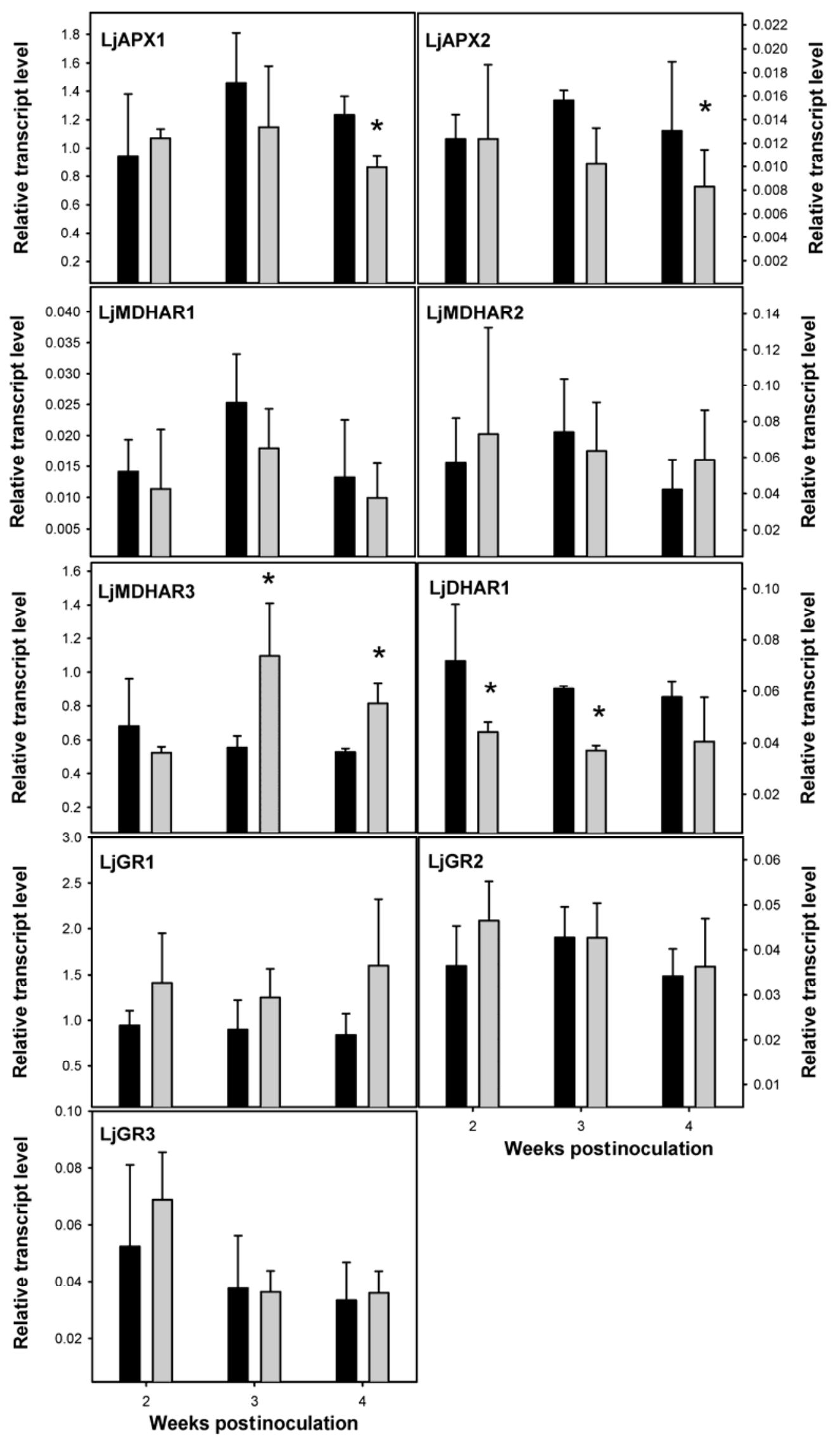

Fig. 2. Expression of genes encoding enzymes of the ascorbate-glutathione cycle. Expression level of two ascorbate peroxidases, $L j A P X 1$ and $L j A P X 2$, three monodehydroascorbate dehydrogenases $L j M D A R 1, L j M D A R 2, L j M D A R 3$, one dehydroascorbate reductase $L j D H A R$, and three glutathione reductases $L j G R 1$, $L j G R 2$, and $L j G R 3$ were measured using quantitative quantitative reverser transcriptase-polymerase chain reaction. Data were normalized against expression levels of ubiquitin10. Black bars represent data from wild-type and gray bars form leghemoglobin-RNA interference nodules. Error bars indicate standard deviation between three independent biological replicates. Significant differences obtained by student $t$-test $(P<0.05)$ are marked by an asterisk. 
GR enzyme activity was significantly lower (between 30 and $40 \%$ lower) in LbRNAi nodules than in the wild-type nodules between 2 and 4 wpi (Fig. 3).

\section{Regulation of cytosolic APX in LbRNAi nodules.}

To test whether the lower APX activities in LbRNAi nodules as compared with the wild type were due to either changes in protein amount or protein Vmax, we performed parallel Western blot and in-gel activity assays. Using total protein extracted from Lotus nodules and a polyclonal antibody raised against a cytosolic soybean ascobate peroxidase (Dalton et al. 1993), a single band was detected via Western blotting at $28 \mathrm{kDa}$, in line with previous results from soybean (Caldwell et al. 1998; Dalton et al. 1987). No difference in the amount of APX protein in LbRNAi and wild-type nodules was detected 2, 3, and 4 wpi (Fig. 4A), indicating that the slightly lower levels of $\mathrm{Lj} A P X 1$ and $\mathrm{Lj} A P X 2$ transcripts in LbRNAi nodules (Fig. 2) did not affect protein amount. In contrast, in-gel activity stain-

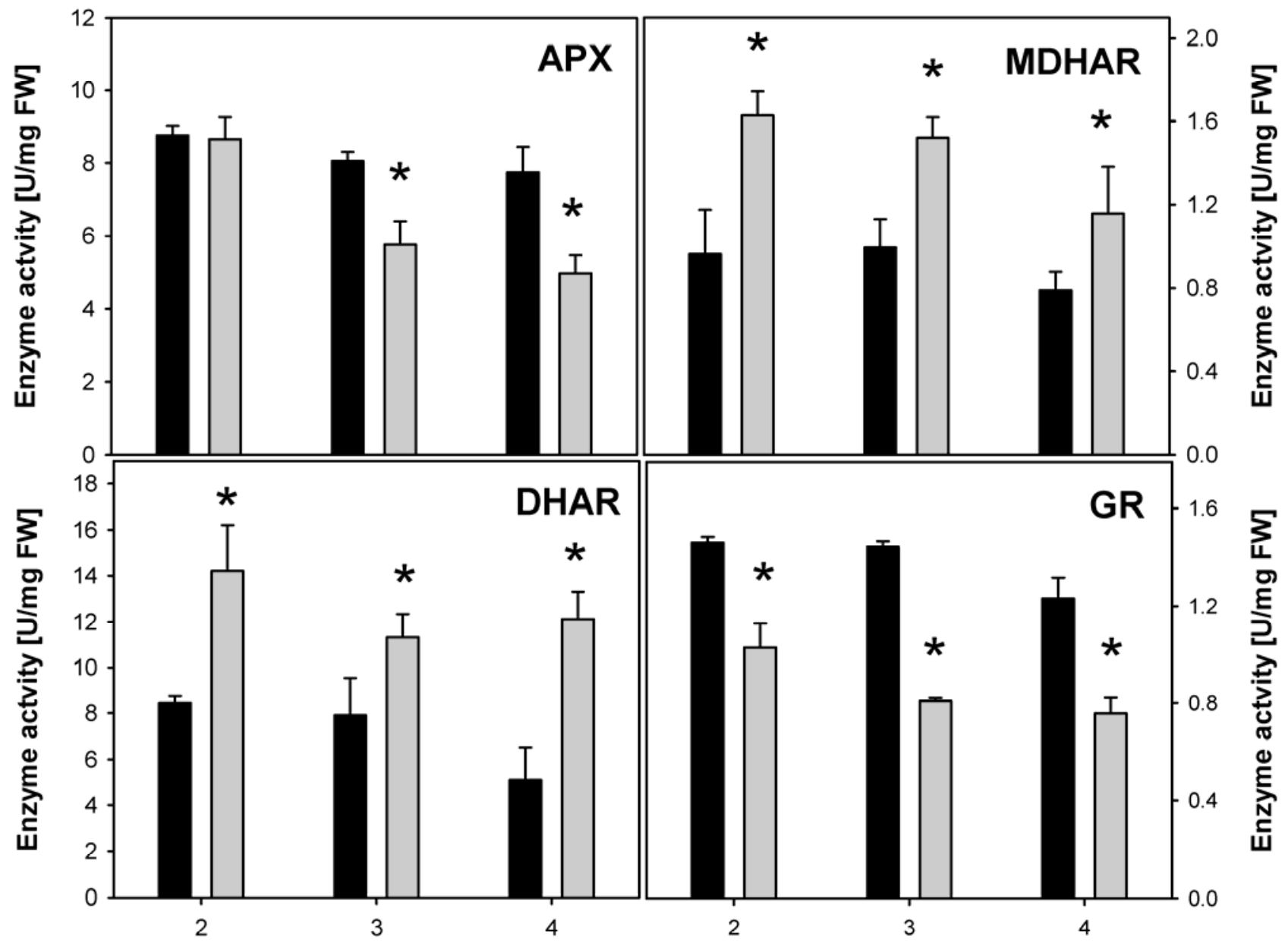

Weeks postinoculation

Weeks postinoculation

Fig. 3. Enzymatic activities of (APX), monodehydroascorbate dehydrogenase (MDHAR), dehydroascorbate reductase (DHAR), and glutathione reductase (GR) in nodules. Enzyme activities of APX, MDHAR, DHAR, and GR were measured in nodules of wild-type (black bars) and transgenic leghemoglobinRNA interference nodules (gray bars). Error bars indicate standard deviation between three independent biological replicates. Significant differences obtained by student $t$-test $(P<0.05)$ are marked by an asterisk.

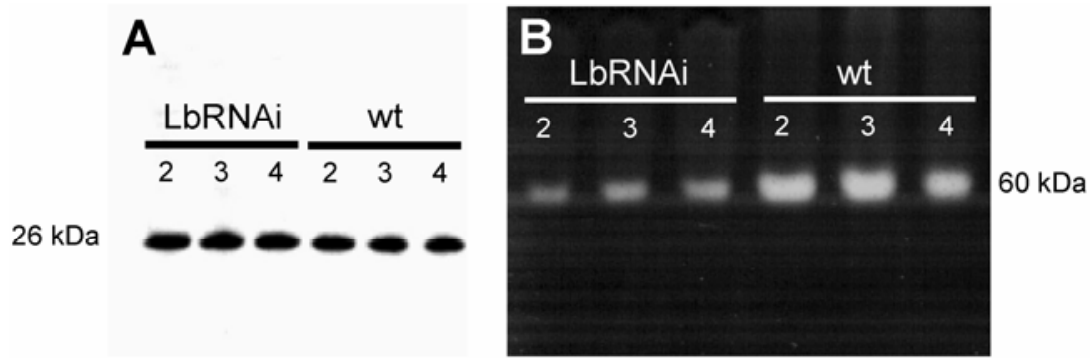

Fig. 4. Detection of ascorbate peroxidase (APX) protein and activity in Lotus root nodule extracts. Total proteins were extracted from nodules of wild-type (wt) and mutant leghemoglobin-RNA interference (LbRNAi) plants at 2, 3, and 4 weeks postinoculation. A, Proteins were separated by sodium dodecyl sulfate-polyacrylamide gel electrophoresis, were blotted onto membrane, and were detected with a specific antibody for APX. B, Native protein gel electrophoresis and enzymatic activities of APX were visualized by ascorbate-dependent reduction of nitroblue tetrazolium. Result shown is representative of three independent experiments that all yielded the same result. 
ing revealed a single active protein band with substantially lower activity in LbRNAi than in wild-type nodules (Fig. 4B), supporting results from in vitro APX assays (Fig. 3).

\section{DISCUSSION}

Autooxidation of leghemoglobins and high rates of respiration have been proposed as major sources of ROS in legume root nodules (Becana and Klucas 1992a and b; Becana and Rodriguez-Barrueco 1989; Becana et al. 1998, 2000; Fridovich 1976; Moreau et al. 1996; Puppo and Halliwell 1988a; Puppo et al. 1981; Schneider and Schlegel 1981). In this study, we assessed the contribution of leghemoglobins to ROS generation in Lotus japonicus nodules by comparing $\mathrm{H}_{2} \mathrm{O}_{2}$ and ascorbate levels and ascorbate-glutathione cycle enzyme transcript, protein, and activity levels in a LbRNAi line devoid of leghemoglobin with those of wild-type plants. The data presented here show for the first time that leghemoglobins are a significant source of ROS in wild-type, nitrogen-fixing legume nodules.

Ascorbate is a key antioxidant in plant ROS metabolism (Noctor and Foyer 1998). Nodules of various legumes were shown to contain either high concentrations of ascorbate (in the millimolar range), elevated activities of antioxidant defense enzymes, or both compared with uninoculated roots (Bashor and Dalton 1999; Dalton et al. 1986; Desbrosses et al. 2005; Gogorcena et al. 1995; Matamoros et al. 1999, 2006). Ascorbate concentrations were found to be about 10-fold higher in nodules than in roots of soybean (Bashor and Dalton 1999), although ascorbate levels of nodules and roots were more similar in nodules of alfalfa, pea, bean, and Lotus japonicus (Matamoros et al. 2006). Concomitant with increases in ascorbate concentration during nodule development, enzymatic activities of APX, DHAR, and MDAR were at least twofold higher in nodules than in roots of soybean and common bean (Dalton et al. 1991, 1996; Jebara et al. 2005). Greater differences in APX activity have been reported in alfalfa, pea, bean, and Lotus japonicus, for which activities were found to be between 12- and 38 -fold higher in nodules compared with roots (Matamoros et al. 2006).

To address the role of leghemoglobins in ROS generation in Lotus nodules, we took advantage of a LbRNAi line that completely lacks these proteins in nodules (Ott et al. 2005). We focused our attention on mature, nitrogen-fixing nodules harvested from roots 2,3 , and 4 weeks after inoculation with rhizobia, which typically contain high levels of leghemoglobins (Ott et al. 2005). Concentrations of $\mathrm{H}_{2} \mathrm{O}_{2}$ and ascorbate remained fairly constant in wild-type nodules between 2 and 4 wpi at approximately 1.2 and $40 \mu \mathrm{mol}$ per milligram of fresh weight, respectively (Fig. 1). Likewise, transcript levels and enzyme activities of APX, MDAR, DHAR, and GR were relatively constant in wild-type nodules between 2 and 4 wpi (Figs. 2 and 3), as was the amount of APX protein (Fig. 4). Loss of leghemoglobin from the RNAi line led to a significant decrease in $\mathrm{H}_{2} \mathrm{O}_{2}$ levels and a significant increase in reduced ascorbate levels in nodules (Fig. 1), consistent with the conclusion that leghemoglobins contribute significantly to ROS production in nodules. Differences in redox homeostasis between wild-type and LbRNAi nodules were partially reflected in changes in the level of transcript for specific enzymes of the ascorbateglutathione cycle; significantly lower levels of LjAPX1, $L j A P X 2$, and $L j G R 1$ transcripts were found in LbRNAi nodules than in the wild type, while the reverse (i.e., significantly higher levels) was true for LjMDAR (Fig. 2). Differences in redox homeostasis between wild-type and LbRNAi nodules were even more apparent at the level of enzymatic activity. LbRNAi nodules had significantly more MDAR and DHAR activity and significantly less APX and GR activity than wild- type nodules (Fig. 3). Taken together with results of transcript analysis (Fig. 2), the data point to significant posttranscriptional regulation of ascorbate-glutathione cycle genes in response to changes in ROS status. DHAR activity was significantly higher in LbRNAi nodules than in the wild type, despite a drop in LjDHAR gene expression, while GR activity was significantly lower in LbRNAi nodules despite no difference between LbRNAi and wild-type nodules in LjGR gene expression (Figs. 2 and 3). This points towards posttranscriptional regulation of both proteins. Indeed, cytoplasmatic GR activities in pea were found to be regulated posttranscriptionally, as elevated levels in PsGR1 transcripts were not reflected in higher enzyme activity (Vanacker et al. 2006). No such data have been published before for nodular DHAR genes.

It remains to be determined whether changes in the activity of the ascorbate-glutathione cycle enzymes in Lotus nodules in response to altered ROS load (Figs. 1, 2, and 3) result from changes in protein concentration rather than protein-specific activity, at least for MDAR, DHAR, and GR. In the case of APX, however, it is clear from the results of Western blot analysis and in-gel activity measurements (Fig. 4) that the decline in APX activity in LbRNAi nodules resulted from posttranslational regulation of APX. Posttranscriptional regulation of APX has been shown in Arabidopsis (Panchuk et al. 2002), Raphanus sativus (Lopez et al. 1996), tobacco (Madhusudhan et al. 2003; Mittler et al. 1998), and pea (Mittler and Zilinskas 1994).

While the work reported here is the first to probe the contribution of leghemoglobins to ROS generation in planta and the results are consistent with the idea that autooxidation of leghemoglobins is a major source of ROS in nodules (Becana and Klucas 1992b; Becana and Rodriguez-Barrueco 1989; Becana et al. 2000; Moreau et al. 1996; Puppo and Halliwell 1988b; Puppo et al. 1981), we cannot exclude the possibility that at least part of the decline in $\mathrm{H}_{2} \mathrm{O}_{2}$ in LbRNAi nodules and the concomitant changes in ascorbate-glutathione cycle activity resulted from indirect effects associated with the loss of leghemoglobins (e.g., the lack of demand for reducing equivalents required for $\mathrm{Lb}$ reducation). We have shown previously that despite the higher concentrations of free oxygen in LbRNAi nodules, respiration appeared to be compromised in these nodules, as judged by a two- to threefold decrease in the ATP/ADP ratio in these nodules compared with the wild type (Ott et al. 2005). If this is indeed the case, then reduced respiration could account for part of the reduction in ROS in LbRNAi nodules. Unfortunately, given the intimate connection between leghemoglobins and respiration in nodules, it may never be possible to separate the two entirely to determine the relative contribution of each to ROS generation. Nonetheless, it is clear from the results presented here that leghemoglobins in nodules, which are necessary for symbiotic nitrogen fixation, lead to ROS generation and an ameliorating response from the ascorbate-glutathione cycle.

\section{MATERIALS AND METHODS}

\section{Biological material.}

Seeds of Lotus japonicus ecotype GIFU (B-129) and its leghemoglobin-deficient LbRNAi line (Ott et al. 2005) were sterilized as described previously and were cultivated in quartz sand (Colebatch et al. 2004) under greenhouse conditions (16h-light and 8-h-dark cycle, $22^{\circ} \mathrm{C}$ ). Plants were inoculated after one week of growth with a 1:50 dilution of a 3-day-old liquid culture of Mesorhizobium loti NZP2235. Nodules were harvested weekly after inoculation and were stored at $-70^{\circ} \mathrm{C}$. Frozen nodules were homogenized using a Retch mixer mill prior to protein or RNA extraction. 


\section{Ascorbate and $\mathrm{H}_{2} \mathrm{O}_{2}$ measurements.}

Ascorbate concentration was measured photometrically, according to a method based on the reduction of dipyridyl (Kampfenkel et al. 1995). Nodules (10 mg) were homogenized and extracted in $100 \mu \mathrm{l}$ of $6 \%$ trichloroacetic acid (TCA). Supernatant $(25 \mu \mathrm{l})$ was mixed with $25 \mu \mathrm{l}$ of $0.4 \mathrm{M}$ sodium-phosphate buffer, $\mathrm{pH} 7.4$, after centrifugation and $100 \mu \mathrm{l}$ of staining reagent (fresh mixture 11:4 of solution $\mathrm{A}[4.6 \%$ TCA, $15.3 \%$ $\left.\mathrm{H}_{3} \mathrm{PO}_{4}\right] / 0.6 \% \mathrm{FeCl}_{3}$ and solution $\mathrm{B}$ [4\% 2,2-dipyridyl in $70 \%$ ethanol]) was added. Supernatant $(100 \mu \mathrm{l})$ was transferred to a 96-well plate after incubation at $42^{\circ} \mathrm{C}$ for $45 \mathrm{~min}$. The extinction coefficient of the red complex was measured at $525 \mathrm{~nm}$.

$\mathrm{H}_{2} \mathrm{O}_{2}$ concentration in nodules was measured fluorimetrically, using the Amplex red $\mathrm{H}_{2} \mathrm{O}_{2}$ and peroxidase assay kit (Invitrogen, Karlsruhe, Germany). The samples were transferred in black 96-well plates and were excited at $530 \mathrm{~nm}$. Emission was detected at $590 \mathrm{~nm}$ and intensity was correlated to $\mathrm{H}_{2} \mathrm{O}_{2}$ concentration using a calibration curve.

\section{qRT-PCR.}

Total RNA was isolated after homogenization of $10 \mathrm{mg}$ of nodules per replicate. Extraction buffer ( $1 \mathrm{ml}$ per sample; 200 mM, pH 9.0, Na-borate, 30 mM EGTA, 1\% sodium dodecyl sulfate [SDS], $1 \%$ Na-deoxycholate, $10 \mathrm{mM}$ dithiothreitol [DTT], $100 \mathrm{mM} \beta$-mercaptoethanol) was heated to $95^{\circ} \mathrm{C}$ and was mixed with the frozen sample. Then, $2 \%$ polyvinylpyrrolidone (PVPP), $0.15 \mathrm{mg}$ proteinase $\mathrm{K}$, and $78 \mu \mathrm{KCl}(2 \mathrm{M})$ were added and the mixture was incubated with slow rotation for approximately $45 \mathrm{~min}$ at $37^{\circ} \mathrm{C}$. The reaction was stopped on ice for approximately $30 \mathrm{~min}$ before the debris was spun down. Nucleic acids were purified via aqueous phenol $(\mathrm{pH}$ 4.5)/chloroform (1:1) extraction using pure chloroform for the first and last extraction step. Nucleic acid precipitation was performed on ice for $45 \mathrm{~min}$ using $0.5 \mathrm{vol}$ of isopropanol. After resuspending the pellet with diethylpyrocarbonate (DEPC)treated water, 1 vol of $\mathrm{LiCl}(4 \mathrm{M})$ was added and the mixture was incubated at $4{ }^{\circ} \mathrm{C}$ overnight. RNA was cleaned using $2 \mathrm{M}$ $\mathrm{LiCl}$ and $70 \%$ ethanol, respectively. Resuspended RNA $(1 \mu \mathrm{l})$ was run on a $1 \%$ agarose gel, and the concentration measured with a NanoDrop spectrometer (NanoDrop, Wilmington, DE, U.S.A.) at $260 \mathrm{~nm}$.

DNA was removed using Turbo RNAse-free DNase (Ambion, Applied Biosystems, Darmstadt, Germany). qRT-PCR was performed to check the success of the digestion using a primer binding in one of the introns of the LjHARl gene (AJ495844) [fwd: 5'-CCTGAAATGCCTATTCGTTGAG-3', rev: 3'-CACA GCTTCTTCTGCATGCG-5']. Dnase-treated RNA $(0.5 \mu \mathrm{g})$ was used for single-stranded cDNA synthesis using SuperScript III reverse transcriptase (Invitrogen) following the manufacturer's protocol.

Samples were diluted 1:8 with DEPC-treated water and were amplified using primers targeting the $3^{\prime}$ end (fwd: 5'-CGGTTA CACTGGAAGATGATGTGG-3', rev: 3'-GATACTTGACCTG TTGTCGCCA-5') and the 5' end (fwd: 5'-AAGGATCGGGC GTTTGG-3', rev: 3'-AGCAACAAGTTCAACATCGTCTCT$5^{\prime}$ ) of a gene encoding a glyceraldehyde 3-phosphate dehydrogenase (TC14070), to ascertain the quality of the cDNA synthesis. Solely, cDNA with a $3^{\prime}: 5^{\prime}$ ratio above 0.98 was used for the experiments.

For expression analysis, replicates were amplified via RTPCR, using gene-specific primers and normalized against ubiquitin10 (TC 14061) [fwd: 5'-TTCACCTTGTGCTCCGTC TTC-3', rev: 3'-AACAACAGCACACACAGACAATCC-5']. Each PCR reaction was carried out in a total volume of $10 \mu \mathrm{l}$, containing $1 \mu \mathrm{l}$ of diluted RNA, $5 \mu \mathrm{l}$ of $2 \times$ SYBR LjGreen PCR MasterMix (Applied Biosystems), and $4 \mu$ of primer mix (0.5 $\mu \mathrm{M}$ each) using a 96- or 386-well Real-Time RT-PCR ma- chine (Applied Biosystems). All RT-PCR steps and calculations of relative transcript levels were performed as described by Czechowski and associates (2004). Primer sequences used for qRT-PCR were as follows.

LjAPX1 (TC 7951): fwd, 5'-CCAACCCTCACATCTTCGACA-3' rev, 3'-ACCTTCCTTCTCACCGGTCAA-5'

LjAPX2 (TC9623): fwd, 5'-GGATGGCATGATGCTGGTACTT-3' rev, 3'-AGCATTAGCTCCACCCCTCTGT-5'

LjMDAR1 (TC12910):

fwd, 5'-CAAACAACCTCTCTCAGCCGAG-3' rev, 3'-TGTCTGAAAGCGACGGAAGTG-5']

LjMDAR2 (TC19086):

fwd, 5'-GCCAAACTTCAAAACGCAACC-3' rev, 3'-TTGCAAGGATCCCCGATTG-5'

LjMDAR3 (TC15657): fwd, 5'-ACATGTTGACCATGCTCGCA-3' rev, 3'-ACTGTTTTCCCATCCTCAGCTG-5'

LjDHAR (TC17380): fwd, 5'-CATTGGTTGCTGAGTTGAGTGC-3' rev, 3'-CCCAGCAACATATGGACCATG-5']

LjGR1 (TC19332): fwd, 5'-CGTGGTTGTGTTCCCAAAAAGA-3' rev, 3'-GCATCCTGAAGTTCACCACCAT-5'

LjGR2 (TC11942): fwd, 5'-AAGGCACAGTTTGACAGCACG-3' rev, 3'-CCGCATGGTCACAAATTCTTCT-5']

LjGR3 (TC16174): fwd, 5'-TACCAACTCCCAAACGAGGAGC-3' rev, 3'-TCCACGTCTTCGTCCGTTGTT-5'

\section{Enzymatic activities.}

Nodules $(20 \mathrm{mg})$ were homogenized and mixed with $1 \%$ PVPP and $600 \mu \mathrm{l}$ of extraction buffer $(0.1 \mathrm{M}$ potassium phosphate buffer ( $\mathrm{pH} 7.8$ ), 1\% Triton X-100, $1 \mathrm{mM}$ benzamidine, 1 $\mathrm{mM} \varepsilon$-amino-capronic acid, $4 \mu \mathrm{M}$ leupeptine, $1 \mathrm{mM}$ phenylmethylsulphonyl fluoride (PMSF), $1 \mathrm{mM}$ DTT, $5 \mathrm{mM}$ ascorbate) for $10 \mathrm{~min}$ at $4^{\circ} \mathrm{C}$. Raw extracts $(0.5 \mathrm{ml})$ were cleaned from proteins $(\mathrm{MW}<5 \mathrm{kDa})$ after centrifugation using NAP-5 columns (Amersham Pharmacia Biotech, Braunschweig, Germany). Enzyme kinetics were measured photometrically in UV-permeable 96 Costar well plates (Vitaris, Baar, Germany) directly after elution in a 96-well Synergy HT microplate reader (Bio-Tek, Winooski, VT, U.S.A.).

APX activity was determined as described by Nakano and Edwards (1987), via the decline of ascorbate absorption at 290 $\mathrm{nm}$.

MDAR activity was measured via the decrease of $\mathrm{NADH}^{+}$ $\mathrm{H}^{+}$at $340 \mathrm{~nm}$ due to oxidation. Ascorbate oxidase $(1.7 \mathrm{U})$ (Sigma, Deisenhofen, Germany) was used for this coupled-enzyme reaction, which was performed according to Borraccino and associates (1981).

DHAR activity was detected by measuring the increase of ascorbate extinction at $265 \mathrm{~nm}$, following a protocol published by Hossain and Asada (1984).

GR activity was assayed as described by Foyer and Halliwell (1976), following the decrease in NADPH at $340 \mathrm{~nm}$.

\section{Native polyacrylamide gel electrophoresis (PAGE) and $A P X$ activity stain.}

Homogenized nodules $(20 \mathrm{mg})$ were mixed in the cold with $100 \mu \mathrm{l}$ of extraction buffer $(0.1 \mathrm{M}$ potassium phosphate buffer, pH 7.0, $1 \mathrm{mM}$ EDTA, 0.1\% Triton X-100, $5 \mathrm{mM}$ ascorbate, 1 $\mathrm{mM}$ benzamidine, $1 \mathrm{mM} \varepsilon$-amino-capronic acid, $4 \mu \mathrm{M}$ leupeptine, $1 \mathrm{mM}$ PMSF, $1 \mathrm{mM}$ DTT). Protein content was determined after centrifugation using Bradford reagent (Sigma). 
Discontinuous polyacrylamide gels $(1 \mathrm{~mm}$; collecting gel, $5 \%$; separating gel, 10\%) without SDS were prepared using a Bio-Rad gel-casting system, following the manufacturer's instructions. Polymerized gels were run in the Mini Protean 3 system (Bio-Rad Laboratories, München, Germany) and were equilibrated in running buffer $(25 \mathrm{mM}$ Tris base, $200 \mathrm{mM}$ glycine, $2 \mathrm{mM}$ ascorbate, $\mathrm{pH} 9.1$ ) for $30 \mathrm{~min}$ at $60 \mathrm{~V}$. Protein extract ( $20 \mu \mathrm{g}$ per well) was applied and electrophoresis was performed at $80 \mathrm{~V}$ for $15 \mathrm{~min}, 100 \mathrm{~V}$ for $20 \mathrm{~min}$, and for $1 \mathrm{~h}$ at $120 \mathrm{~V}$.

APX activity was visualized by negative bands on a purpleblue gel due to inhibition of the ascorbate-dependent reduction of nitroblue tetrazolium (NBT; Roche, Mannheim, Germany), according to the method of Mittler and Zilinskas 1993).

\section{Western blot hybridization.}

Nodules $(15 \mathrm{mg}$ ) were homogenized, were mixed with extraction buffer (10 mM Tris, $140 \mathrm{mM} \mathrm{NaCl}, 5 \mathrm{mM}$ EDTA, $1 \%$ Triton X-100, $1 \mathrm{mM}$ PMSF, $1 \mathrm{mM}$ DTT), and were centrifuged. Protein content of the supernatant was determined photometrically after using Bradford reagent. Protein extract $(10 \mu \mathrm{g})$ was denatured by adding 0.25 vol loading buffer ( $40 \%$ glycerin, $20 \% \beta$-mercaptoethanol, $400 \mathrm{mM}$ Tris/ $\mathrm{HCl}, \mathrm{pH} 6.8,7 \%$ SDS, $0,1 \%$ bromophenolblue) and was incubated at $95^{\circ} \mathrm{C}$ for 10 min. Proteins were separated by SDS-PAGE on a precasted $10 \%$ Bis-Tris gel (Invitrogen) according to the manufacturer's instructions. Proteins were transferred to a Protran nitrocellulose membrane (Whatman/Schleicher \& Schuell, Einbeck, Germany) by using the XCell II blot module (Invitrogen), following the protocol provided by the manufacturer. Successful transfer was controlled by Red Ponceau staining (Sigma) of the membrane.

The membrane was blocked in phosphatesaline (PBS) buffer, $2 \%$ milk powder, $3 \%$ bovine serum albumin before being incubated overnight at $4^{\circ} \mathrm{C}$ with APX antibody. The membrane was incubated for $2 \mathrm{~h}$ with the secondary antibody (antirabbit immunoglobulin $\mathrm{G}$ alkaline phosphatase) after washing in PBS buffer containing $0.1 \%$ Tween 20 and $0.5 \%$ Tween 20 , $1 \mathrm{M} \mathrm{NaCl}$ for $10 \mathrm{~min}$, respectively. Washing steps were repeated and the membrane was incubated in $100 \mathrm{mM}$ Tris base ( $\mathrm{pH} 9.0)$ before NBT/5-bromo-4-chloro-3-indolyl phosphate staining.

\section{ACKNOWLEDGMENTS}

We thank D. Sahid for excellent technical help and Y. Gibon for advice and help during enzymatic activity assays and the Max-Planck-Society for financial support. APX antibody was a kind gift from D. Dalton (Reed College, Portland, OR, U.S.A.).

\section{LITERATURE CITED}

Appleby, C. A. 1984. Leghemoglobin and Rhizobium respiration. Ann. Rev. Plant Physiol. Plant Mol. Biol. 35:443-478.

Barker, D. G., Gallusci, P., Lullien, V., Khan, H., Gherardi, M., and Huguet, T. 1988. Identification of 2 groups of leghemoglobin genes in alfalfa (Medicago sativa) and a study of their expression during root nodule development. Plant Mol. Biol. 11:761-772.

Bashor, C. J., and Dalton, D. A. 1999. Effects of exogenous application and stem infusion of ascorbate on soybean (Glycine max) root nodules. New Phytol. 142:19-26.

Becana, M., and Klucas, R. V. 1992a. Oxidation and reduction of leghemoglobin in root nodules of leguminous plants. Plant Physiol. 98:12171221.

Becana, M., and Klucas, R.V. 1992b. Transition metals in legume root nodules: Iron-dependent free radical production increases during nodule senescence. Proc. Natl. Acad. Sci. U.S.A. 89:8958-8962.

Becana, M., and Rodriguez-Barrueco, C. 1989. Protective mechanisms of nitrogenase against oxygen excess and partially-reduced oxygen intermediates. Physiol. Plantarum 75:429-438.

Becana, M., Moran, J. F., and Iturbe-Ormaetxe, I. 1998. Iron-dependent oxygen free radical generation in plants subjected to environmental stress: Toxicity and antioxidant protection. Plant Soil 201:137-147.

Becana, M., Dalton, D. A., Moran, J. F., Iturbe-Ormaetxe, I., Matamoros, M. A., and Rubio, M. C. 2000. Reactive oxygen species and antioxidants in legume nodules. Physiol. Plantarum 109:372-381.

Bergersen, F. J. 1996. Delivery of $\mathrm{O}_{2}$ to bacteroids. Protoplasma 191:9-20.

Bergersen, F.J., and Goodchil, D. J. 1973. Aeration pathways in soybean root nodules. Aust. J. Biol. Sci. 26:729-740.

Bogusz, D., Appleby, C. A., Landsmann, J., Dennis, E. S., Trinick, M. J., and Peacock, W. J. 1988. Functioning hemoglobin genes in non-nodulating plants. Nature 331:178-180.

Borraccino, G., Dipierro, S., and Arrigoni, O. 1981. Interaction of ascorbate free-radical reductase with sulphydryl-reagents. Phytochemistry 28:715-717.

Caldwell, C. R., Turano, F. J., and McMahon, M. B. 1998. Identification of two cytosolic ascorbate peroxidase cDNAs from soybean leaves and characterization of their products by functional expression in E. coli. Planta 204:120-126.

Colebatch, G., Kloska, S., Trevaskis, B., Freund, S., Altmann, T., and Udvardi, M. K. 2002. Novel aspects of symbiotic nitrogen fixation uncovered by transcript profiling with cDNA arrays. Mol. Plant-Microbe Interact. 15:411-420.

Colebatch, G., Desbrosses, G., Ott, T., Krusell, L., Montanari, O., Kloska, S., Kopka, J., and Udvardi, M. K. 2004. Global changes in transcription orchestrate metabolic differentiation during symbiotic nitrogen fixation in Lotus japonicus. Plant J. 39:487-512.

Contour-Ansel, D., Torres-Franklin, M. L., Cruz, D. E. C. M. H., D’ArcyLameta, A., and Zuily-Fodil, Y. 2006. Glutathione reductase in leaves of cowpea: Cloning of two cDNAs, expression and enzymatic activity under progressive drought stress, desiccation and abscisic acid treatment. Ann. Bot. (Lond) 98:1279-1287.

Czechowski, T., Bari, R. P., Stitt, M., Scheible, W. R., and Udvardi, M. K. 2004. Real-time RT-PCR profiling of over 1400 Arabidopsis transcription factors: Unprecedented sensitivity reveals novel root- and shootspecific genes. Plant J. 38:366-379.

Dakora, F. D. 1995. A functional relationship between leghemoglobin and nitrogenase based on novel measurements of the two proteins in legume root nodules. Ann. Bot. 75:49-54.

Dalton, D. A., Russell, S. A., Hanus, F. J., Pascoe, G. A., and Evans, H. J. 1986. Enzymatic reactions of ascorbate and glutathione that prevent peroxide damage in soybean root nodules. Proc. Natl. Acad. Sci. U.S.A. 83:3811-3815

Dalton, D. A., Hanus, F. J., Russell, S. A., and Evans, H. J. 1987. Purification, properties, and distribution of ascorbate peroxidase in legume root nodules. Plant Physiol. 83:789-794

Dalton, D. A., Post, C. J., and Langeberg, L. 1991. Effects of ambient oxygen and of fixed nitrogen on concentrations of glutathione, ascorbate, and associated enzymes in soybean root nodules. Plant Physiol. 96:812818.

Dalton, D. A., Baird, L. M., Langeberg, L., Taugher, C. Y., Anyan, W. R., Vance, C. P., and Sarath, G. 1993. Subcellular localization of oxygen defense enzymes in soybean (Glycine max [L.] Merr.) root nodules. Plant Physiol. 102:481-489.

Dalton, D. A., Diaz del Castillo, L., Kahn, M. L., Joyner, S. L., and Chatfield, J. M. 1996. Heterologous expression and characterization of soybean cytosolic ascorbate peroxidase. Arch Biochem Biophys 328:1-8.

Davidowitz, E. J., Cullis, C. A., and Langunnasch, N. 1994. MessagerRNA from diverse classes of alfalfa leghemoglobin genes show a similar pattern of spatial expression in symbiotic root nodules. Plant Soil 162:303-307.

Denison, R. F., and Layzell, D. B. 1991. Measurement of legume nodule respiration and $\mathrm{O}_{2}$ permeability by noninvasive spectrophotometry of leghemoglobin. Plant Physiol. 96:137-143.

Desbrosses, G. G., Kopka, J., and Udvardi, M. K. 2005. Lotus japonicus metabolic profiling. Development of gas chromatography-mass spectrometry resources for the study of plant-microbe interactions. Plant Physiol. 137:1302-1318.

El Yahyaoui, F., Kuster, H., Ben Amor, B., Hohnjec, N., Puhler, A., Becker, A., Gouzy, J., Vernie, T., Gough, C., Niebel, A., Godiard, L., and Gamas, P. 2004. Expression profiling in Medicago truncatula identifies more than 750 genes differentially expressed during nodulation, including many potential regulators of the symbiotic program. Plant Physiol. 136:3159-3176.

Fedorova, M., van de Mortel, J., Matsumoto, P. A., Cho, J., Town, C. D., VandenBosch, K. A., Gantt, J. S., and Vance, C. P. 2002. Genome-wide identification of nodule-specific transcripts in the model legume Medicago truncatula. Plant Physiol. 130:519-537.

Foyer, C. H., and Halliwell, B. 1976. Presence of glutathione and glutathione reductase in chloroplasts-proposed role in ascorbic acid metabolism. Planta 133:21-25. 
Fridovich, I. 1976. Superoxide dismutases: Studies of structure and mechanism. Adv. Exp. Med. Biol. 74:530-539.

Gallusci, P., Dedieu, A., Journet, E. P., Huguet, T., and Barker, D. G. 1991. Synchronous expression of leghaemoglobin genes in Medicago truncatula during nitrogen-fixing root nodule development and response to exogenously supplied nitrate. Plant Mol. Biol. 17:335-349.

Gogorcena, Y., Iturbe-Ormaetxe, I., Escuredo, P. R., and Becana, M. 1995 Antioxidant defenses against activated oxygen in pea nodules subjected to water stress. Plant Physiol. 108:753-759.

Hargrove, P. W., Vanin, E. F., Kurtzman, G. J., and Nienhuis, A. W. 1997. High-level globin gene expression mediated by a recombinant adenoassociated virus genome that contains the $3^{\prime}$ gamma globin gene regulatory element and integrates as tandem copies in erythroid cells. Blood 89:2167-2175.

Hossain, M. A., and Asada, K. 1984. Purification of dehydroascorbate reductase from spinach and its characterization as a thiol enzyme. Plant Cell Physiol. 25:85-92.

Hunt, S., and Layzell, D. B. 1993. Gas-exchange of legume nodules and the regulation of nitrogenase activity. Ann. Rev. Plant Physiol. Plant Mol. Biol. 44:483-511.

Jebara, S., Jebara, M., Limam, F., and Aouani, M. E. 2005. Changes in ascorbate peroxidase, catalase, guaiacol peroxidase and superoxide dismutase activities in common bean (Phaseolus vulgaris) nodules under salt stress. J. Plant Physiol. 162:929-936.

Ji, L., Becana, M., and Klucas, R. V. 1992. Involvement of molecular oxygen in the enzyme-catalyzed NADH oxidation and ferric leghemoglobin reduction. Plant Physiol. 100:33-39

Journet, E. P., van Tuinen, D., Gouzy, J., Crespeau, H., Carreau, V., Farmer, M. J., Niebel, A., Schiex, T., Jaillon, O., Chatagnier, O., Godiard, L., Micheli, F., Kahn, D., Gianinazzi-Pearson, V., and Gamas, P.. 2002. Exploring root symbiotic programs in the model legume Medicago truncatula using EST analysis. Nucleic Acids Res. 30:5579-5592.

Kampfenkel, K., Van Montagu, M., and M., Inze, D. 1995. Extraction and determination of ascorbate and dehydroascorbate from plant tissue. Anal. Biochem. 225:165-167.

Kouchi, H., Shimomura, K., Hata, S., Hirota, A., Wu, G. J., Kumagai, H., Tajima, S., Suganuma, N., Suzuki, A., Aoki, T., Hayashi, M., Yokoyama, T., Ohyama, T., Asamizu, E., Kuwata, C., Shibata, D., and Tabata, S. 2004. Large-scale analysis of gene expression profiles during early stages of root nodule formation in a model legume, Lotus japonicus. DNA Res. 11:263-274.

Lopez, F., Vansuyt, G., Casse-Delbart, F., and Fourcroy, F. 1996. Ascorbate peroxidase activity, not the mRNA level, is enhanced in saltstressed Raphanus sativus plants. Physiol. Plantarum 97:13-20

Madhusudhan, R., Ishikawa, T., Sawa, Y., Shigeoka, S., and Shibata, H. 2003. Characterization of an ascorbate peroxidase in plastids of tobacco BY-2 cells. Physiol. Plant 117:550-557.

Marchal, K., and Vanderleyden, J. 2000. The "oxygen paradox" of dinitrogen-fixing bacteria. Biol. Fertil. Soils 30:363-373.

Matamoros, M. A., Baird, L. M., Escuredo, P. R., Dalton, D. A., Minchin, F. R., Iturbe-Ormaetxe, I., Rubio, M. C., Moran, J. F., Gordon, A. J., and Becana, M. 1999. Stress-induced legume root nodule senescence. Physiological, biochemical, and structural alterations. Plant Physiol. 121:97-112

Matamoros, M. A., Dalton, D. A., Ramos, J., Clemente, M. R., Rubio, M. C., and Becana, M. 2003. Biochemistry and molecular biology of antioxidants in the rhizobia-legume symbiosis. Plant Physiol. 133:499-509.

Matamoros, M. A., Loscos, J., Coronado, M. J., Ramos, J., Sato, S., Testillano, P. S., Tabata, S., and Becana, M. 2006. Biosynthesis of ascorbic acid in legume root nodules. Plant Physiol. 141:1068-1077.

Mittler, R. 2002. Oxidative stress, antioxidants and stress tolerance. Trends Plant Sci. 7:405-410.

Mittler, R., and Zilinskas, B. A. 1993. Detection of ascorbate peroxidase activity in native gels by inhibition of the ascorbate-dependent reduction of nitroblue tetrazolium. Anal. Biochem. 212:540-546.

Mittler, R., and Zilinskas, B. A. 1994. Regulation of pea cytosolic ascorbate peroxidase and other antioxidant enzymes during the progression of drought stress and following recovery from drought. Plant J. 5:397-405.

Mittler, R., Feng, X., and Cohen, M. 1998. Post-transcriptional suppression of cytosolic ascorbate peroxidase expression during pathogen-induced programmed cell death in tobacco. Plant Cell 10:461-474.

Moreau, S., Davies, M. J., Mathieu, C., Herouart, D., and Puppo, A. 1996. Leghemoglobin-derived radicals. Evidence for multiple protein-derived radicals and the initiation of peribacteroid membrane damage. J. Biol. Chem. 271:32557-32562.

Nakano, Y., and Edwards, G. E. 1987. Hill reaction, hydrogen peroxide scavenging, and ascorbate peroxidase activity of mesophyll and bundle sheath chloroplasts of NADP-malic enzyme type C(4) species. Plant Physiol. 85:294-298.

Noctor, G., and Foyer, C. H. 1998. Ascorbate and glutathione: Keeping active oxygen under control. Annu. Rev. Plant Phys. 49:249-279.

Ott, T., van Dongen, J. T., Gunther, C., Krusell, L., Desbrosses, G. Vigeolas, H., Bock, V., Czechowski, T., Geigenberger, P., and Udvardi, M. K. 2005. Symbiotic leghemoglobins are crucial for nitrogen fixation in legume root nodules but not for general plant growth and development. Curr. Biol. 15:531-535.

Panchuk, I. I., Volkov, R. A., and Schoffl, F. 2002. Heat stress- and heat shock transcription factor-dependent expression and activity of ascorbate peroxidase in Arabidopsis. Plant Physiol. 129:838-853.

Puppo, A., and Halliwell, B. 1988a. Formation of hydroxyl radicals from hydrogen peroxide in the presence of iron. Is haemoglobin a biological Fenton reagent? Biochem. J. 249:185-190.

Puppo, A., and Halliwell, B. 1988b. Formation of hydroxyl radicals in biological systems. Does myoglobin stimulate hydroxyl radical formation from hydrogen peroxide? Free Radical Res. Com. 4:415-422.

Puppo, A., Rigaud, J., and Job, D. 1981. Role of superoxide anion in leghemoglobin autooxidation. Plant Sci. Lett. 22:353-360.

Robson, R. L., and Postgate, J. R. 1980. Oxygen and hydrogen in biological nitrogen-fixation. Annu. Rev. Microbiol. 34:183-207.

Sato, T., Onoma, N., Sueyoshi, K., and Ohyama, T. 2001. Changes in four leghemoglobin components in nodules of hypernodulating soybean (Glycine $\max [\mathrm{L}]$ Merr.) mutant and its parent in the early nodule developmental stage. Plant Soil 237:129-135.

Schneider, K., and Schlegel, H.G. 1981. Production of superoxide radicals by soluble hydrogenase from Alcaligenes eutrophus H16. Biochem. J. 193:99-107.

Sheehy, J. E., Minchin, F. R., and Witty, J. F. 1985. Control of nitrogenfixation in a legume nodule-An analysis of the role of oxygen diffusion in relation to nodule structure. Ann. Bot. London 55:549-562.

Shigeoka, S., Ishikawa, T., Tamoi, M., Miyagawa, Y., Takeda, T., Yabuta, Y., and Yoshimura, K. 2002. Regulation and function of ascorbate peroxidase isoenzymes. J. Exp. Bot. 53:1305-1319.

Stougaard, J., Petersen, T. E., and Marcker, K. A. 1987. Expression of a complete soybean leghemoglobin gene in root-nodules of transgenic Lotus-Corniculatus. Proc. Natl. Acad. Sci. U.S.A. 84:5754-5757.

Sunkar, R., Kapoor, A., and Zhu, J. K. 2006. Posttranscriptional induction of two $\mathrm{Cu} / \mathrm{Zn}$ superoxide dismutase genes in Arabidopsis is mediated by downregulation of miR398 and important for oxidative stress tolerance. Plant Cell 18:2051-2065.

Tjepkema, J. D., and Yocum, C. S. 1974. Measurement of oxygen partial pressure within soybean nodules by oxygen microelectrodes. Planta $119: 351-360$

Trevaskis, B., Watts, R. A., Andersson, C. R., Llewellyn, D. J., Hargrove, M. S., Olson, J. S., Dennis, E. S., and Peacock, W. J. 1997. Two hemoglobin genes in Arabidopsis thaliana: The evolutionary origins of leghemoglobins. Proc. Natl. Acad. Sci. U.S.A. 94:12230-12234.

Uchiumi, T., Shimoda, Y., Tsuruta, T., Mukoyoshi, Y., Suzuki, A., Senoo, K., Sato, S., Kato, T., Tabata, S., Higashi, S., and Abe, M. 2002. Expression of symbiotic and nonsymbiotic globin genes responding to microsymbionts on Lotus japonicus. Plant Cell Physiol. 43:1351-1358.

Vanacker, H., Sandalio, L., Jimenez, A., Palma, J. M, Corpas, F. J., Meseguer, V., Gomez, M., Sevilla, F., Leterrier, M., Foyer, C. H, and del Rio, L. A. 2006. Roles for redox regulation in leaf senescence of pea plants grown on different sources of nitrogen nutrition. J. Exp. Bot. 57:1735-1745.

Webb, J., and Sheehy, J. E. 1991. Legume nodule morphology with regard to oxygen diffusion and nitrogen-fixation. Ann. Bot. 67:77-83.

Wittenberg, J. B., Wittenberg, B. A., and Appleby, C. A. 1972. Kinetics of reactions of leghemoglobin with oxygen and carbon-monoxide. J. Biol. Chem. 247:527-536.

Wittenberg, J. A., Bergersen, F. J., Appleby, C. A., and Turner, G. L. 1974. Facilitated oxygen diffusion. The role of leghemoglobin in nitrogen fixation by bacteroids isolated from soybean root nodules. J. Biol. Chem. 249:4057-4066.

Witty, J. F., and Minchin, F. R. 1998. Hydrogen measurements provide direct evidence for a variable physical barrier to gas diffusion in legume nodules. J. Exp. Bot. 49:1015-1020.

\section{AUTHOR-RECOMMENDED INTERNET RESOURCE}

The Gene Index Project: compbio.dfci.harvard.edu/tgi/plant.html 